\title{
The role of social and/or ecological contexts influences assessment strategy use in Tilapia
}

\author{
Sara L. Stienecker ${ }^{1,2}$ (D) | Kelly M. Jackson ${ }^{1,2}$ | Paul A. Moore Pa $^{1,2,3}$
}

${ }^{1}$ Laboratory for Sensory Ecology, Department of Biological Sciences, Bowling Green State University, Bowling Green, Ohio ${ }^{2}$ University of Michigan Biological Station, Pellston, Michigan

${ }^{3}$ J.P. Scott Center for Neuroscience, Mind and Behavior, Bowling Green State University, Bowling Green, Ohio

\section{Correspondence \\ Paul A. Moore, Department of Biological Sciences, Bowling Green State University, Bowling Green, $\mathrm{OH} 43403$. \\ Email: pmoore@bgsu.edu \\ Funding information \\ Swedish Fulbright Commission; BGSU FRC Grant}

Editor: J. Schneider

\begin{abstract}
Animals engage in costly agonistic contests during which winners procure resources. During these interactions, the combatants obtain and use information to make decisions on whether to persist or to withdraw from the fight, which is termed assessment. Recent theory and work have suggested that the types of assessment employed may be more variable than previously thought, with the use of different strategies possibly being influenced by social and ecological conditions during priming. This study addresses the contextual components (social and ecological) that affect the utilization of one assessment strategy over another. Male tilapia were primed with different combinations of social (large and small animals) and ecological (resource rich or poor) contexts $24 \mathrm{hr}$ prior to fighting in staged, dyadic contests. When opponents were primed with the same context, a clear assessment strategy emerged and differed as a function of priming treatment. Conversely, when fish were primed with different treatment contexts, there was no discernible assessment. In addition, priming conditions had differing effects for large and small fish. Thus, assessment strategies in cichlids are dependent upon a combination of social, ecological contexts and size of the animal. Since assessment strategies change as a function of both of these contexts, as well as others, future framework investigating assessment strategies should include both intrinsic and extrinsic factors that may shape fighting dynamics.
\end{abstract}

\section{KEYWORDS}

assessment strategies, fighting, information, tilapia

\section{1 | INTRODUCTION}

Aggressive interactions arise frequently in animal populations as a result of competition over resources (Maynard Smith \& Price, 1973; Parker, 1974). Contest outcomes (i.e., winners and losers), and therefore resource acquisition, are a direct result of the decisions animals make about ending fights. Decision-making regarding agonistic interactions can be separated into three distinct stages: (1) engagement in a contest, (2) escalation or de-escalation during a contest and, finally (3) the decision to retreat or end a contest (Enquist \& Leimar, 1983). The choice to engage in an agonistic interaction is influenced by costs and benefits (Maynard Smith \& Price, 1973). Costs of fights may include injury, loss of time and energy and even death, whereas benefits of winning fights consist of access to resources including food, shelter and mates (Bertram, Rook, Fitzsimmons, \& Fitzsimons, 2011; Hack, 1997a; Kokko, 2013). These differing costs and benefits vary within and across species. During a fight, opponents use information gathered from distinctive sources to determine whether to escalate the intensity of the fight (Maynard Smith \& Parker, 1976; Parker, 1974). The final decision to retreat or end a fight is based on the costs and benefits accumulated from persistence versus the costs and benefits of exiting an interaction (Maynard Smith \& Parker, 1976; Parker, 1974). Specifically, opponents should assess, as well as differentiate, if and when the costs of persistence are too high and 
thus withdraw from the fight. Contests should compare the costs of persistence to the benefits of escalating the fight in the chance of obtaining resources (Arnott \& Elwood, 2008; Maynard Smith, 1974; Maynard Smith \& Parker, 1976; Taylor \& Elwood, 2003). Both information acquisition and utilization are critical aspects for animals to make an accurate decision about withdrawing from the contest and have been shaped by natural selection (Arnott \& Elwood, 2008).

Assessment strategies are employed by animals during agonistic interactions to determine when to leave a fight (Arnott \& Elwood, 2009; Mesterton-Gibbons \& Heap, 2014; Parker, 1974). Multiple strategies are used and can be discriminated by the type of information the animal is theorized to be utilizing to make decisions. There are two broad categories of information used during assessment, termed public and private information, with different costs and benefits associated with employing one over the other (Dabelsteen, 2005; Mesterton-Gibbons \& Heap, 2014). Public information is information about the fighting ability of an opponent (known as Resource Holding Potential, or Resource Holding Power, both termed RHP) as well as distribution of fighting abilities within the local population of potential contestants (Johnsson \& Åkerman, 1998; Matos \& Schlupp, 2005; Mesterton-Gibbons \& Heap, 2014; Sherratt \& Mesterton-Gibbons, 2013). Public information on fighting ability is obtained by monitoring the opponent's use of displays and signals (Arnott \& Elwood, 2007; Clutton-Brock \& Albon, 1979; Fitzsimmons \& Bertram, 2013; Jennings \& Gammel, 2013; Lougue et al., 2010; Mesterton-Gibbons \& Sherratt, 2006). Additionally, this type of information incurs the cost of energy expenditure, the potential of exposing the animal's own fighting ability and reallocating time spent that could have been used for other activities (Hack, 1997b; Mesterton-Gibbons \& Heap, 2014). Potential mates can also utilize public information from fight outcomes as a measurement for mate quality (Doutrelant \& McGregor, 2000; Doutrelant, McGregor, \& Oliveira, 2001; Montroy, Loranger, \& Bertram, 2016; Otter \& Ratcliffe, 2005). Private information about RHP consists of information on an individual's ability such as stamina, past fighting history, energy thresholds or strength. Thus, assessment strategies can be placed along an information use spectrum (Mesterton-Gibbons \& Heap, 2014; Prenter, Elwood, \& Taylor, 2006). At one end of the spectrum sits self-assessment, where animals rely solely on private information about RHP (Arnott \& Elwood, 2009). At the other end of the spectrum, mutual assessment is employed by animals that not only consider private information, but then compare private information with public information about the opponents or local population (Arnott \& Elwood, 2009).

Historically, the theoretical framework for assessment strategies has been based upon the concept that assessment strategies are fairly static within species and across an individual's lifetime (Arnott \& Elwood, 2009; Elwood \& Arnott, 2012; Fawcett \& Mowles, 2013; Taylor \& Elwood, 2003). However, recent results from behavioural work have called this assumption into question. For example, jumping spiders (Phidippus clarus) utilize a mixed assessment strategy during agonistic contests as a function of experience (Elias, Kasumovic, Punzalan, Andrade, \& Mason, 2008). Killifish
(Kryptolebias marmoratus) also do not follow classic models, in that they switch assessment strategies over the course of a fight by adopting a mutual assessment strategy at early stages of the fight, then switching to a self-assessment strategy after the fight has escalated (Hsu, Lee, Chen, Yang, \& Cheng, 2008). Finally, Camerlink, Turner, Farish, and Arnott (2017) found that increased social experience causes wild boars (Sus scrofa) to change from a mutual assessment to self-assessment strategy. These results together present a concept where assessment strategies are dynamic and depend upon the social and ecological contexts under which populations of organisms interact. The social dynamics that exist within a population are constantly fluctuating, as dominance hierarchies are established and challenged, and as individuals immigrate and emigrate over time (Chase, Tovey, Spangler-Martin, \& Manfredonia, 2002; Hsu, Earley, $\&$ Wolf, 2006). The ongoing process of immigration and emigration also disrupts the distribution of RHP within a population, as well as changes the ratio of strong to weak individuals regularly (Pulliam, 1998). In addition, resource richness and availability fluctuates, both temporally and spatially. The patchy nature of resource distribution creates pockets of uneven levels of competition because the costs and benefits tied to those spatially patchy resources dictate the level of competition.

To better reflect natural systems, assessment strategy theory has been updated to a more dynamic model that includes the influence of these social and ecological factors on contest resolution (Mesterton-Gibbons \& Heap, 2014). In this newer theoretical framework, assessment strategy utilization is expected to change as a function of social and ecological contextual fluctuations. Within this model, one axis of context was relative resource value (or rich/poor resource environments) and the other axis was relative proportion of weak RHP individuals (or ratio of strong to weak individuals). This distribution creates four corner boundary conditions: resource-rich/strong-skewed, resource-rich/weak-skewed, resource-poor/strong-skewed and resource-poor/weak-skewed. Evolutionary stable strategies (ESS) arose from this distribution such that in two corners there were ESS assessment strategies (rich/strong, poor/weak), in one corner several strategies converged (rich/weak), and in the final corner there was a conventional system where strong individuals always persisted and weak always withdrew. Within the rich/strong area of the model, populations were deemed "careful" where strong individuals applied a mutual assessment strategy and weak individuals adopted a self-assessment strategy. In the opposite area (poor/weak), populations were labelled "daring" and the assessment strategies between strong and weak individuals were reversed (MestertonGibbons \& Heap, 2014). Thus, these two areas of the model (poor/ weak and rich/strong) provide a chance to ascertain the assessment strategy of single-species populations under different conditions. The underlying reason for switches in assessment strategy was based on the costs of information acquisition as measured against the perceived value of resources. In the model, self-assessment was favoured when the cost of mutual assessment was high, while mutual assessment was favoured when the cost of mutual 
assessment was low relative to the cost of a fight. As resource richness decreases (resource value increases), self-assessment was favoured for strong individuals while mutual assessment was preferred for weaker individuals. Specifically, assessment strategy selection was expected to differ between strong and weak individuals within the same population, based on contest history and physical state.

The suggestion that assessment utilization is more fluid than previously thought has yet to be extensively tested empirically. Furthermore, the experimental understanding of assessment is based heavily on controlled, staged fights with little or no previous social experience, although recent work shows these experiences are important for the development of assessment (Camerlink et al., 2017). Therefore, the influence of the social environment on contest resolution is not well understood. This study addresses these gaps in knowledge using tilapia (Oreochromis aureus $x$ Oreochromis niloticus, hybrid) and explores the influence that both social and ecological contextual factors have on the way animals make decisions about withdrawal (i.e., assessment strategy employment). Within the Mesterton-Gibbons and Heap (2014) model, the resource-poor/ weak-skewed (PW) populations and resource-rich/strong-skewed (RS) populations yielded clear assessment strategies. Within PW populations, strong individuals employed mutual assessment while weak individuals use self-assessment. In RS populations, strong individuals utilize self-assessment and weak individuals use mutual assessment. The other two groups, resource-poor/strong-skewed (PS) and resource-rich/weak-skewed populations (RW) had no discernible assessment strategies based on the model. Thus, we chose to focus our work on that part of the model that produced clear assessment predictions. Based on the application of the model developed by Mesterton-Gibbons and Heap (2014) to this system, we hypothesized that strong and weak individuals will adopt different assessment strategies from agonistic interactions in all the environments. In addition, strong individuals are expected to employ a self-assessment strategy in resource-poor/weak-skewed environments and mutual assessment in resource-rich/strong-skewed environments. Weak individuals are hypothesized to reverse this assessment strategy employment and use mutual assessment in the resource-poor/ weak-skewed environment, as well as self-assessment in the resource-rich/strong-skewed environment.

\section{2 | METHODS}

\subsection{Animal housing and care}

Two-hundred thirty blue tilapia $\mathrm{X}$ white Nile tilapia (Oreochromis aureus $X$ Oreochromis niloticus) all-male hybrid fingerlings were purchased from White Brooke Tilapia Farm (MO, USA). We specifically chose this hybrid to ensure that sex was not a confounding variable. Fish were brought to the University of Michigan Biological Station (UMBS) Stream Research Facility (Pellston, MI, USA) and were communally housed in 10-gallon fish aquaria with unfiltered river water from the East branch of the Maple River (Pellston, MI) $\left(20^{\circ} \mathrm{C}\right)$. During this period, fish were fed four times daily with commercial tilapia food pellets (AlliedAqua, 1/16" pellets). All animals were kept on a natural photocycle ( 15h:9h; L:D).

After three weeks residing in communal housing, fish were isolated. Each fish was measured for total length $(T L)$ in centimetres to the nearest millimetre and placed into a modified deli container (Genpak AD64, 2 Qt. Clear Hinged Deli Container; $20.32 \mathrm{~cm} \times 21.59 \mathrm{~cm} \times 8.255 \mathrm{~cm} ; \mathrm{L} \times \mathrm{W} \times \mathrm{H}$ ) with holes $(7.62 \mathrm{~cm} \times 7.62 \mathrm{~cm} ; \mathrm{L} \times \mathrm{W})$ cut into the four side walls of the container and covered with mesh window screening. The deli containers were then put into a flow-through, donut-shaped, artificial stream constructed from cinderblocks and 6 mil $(0.015 \mathrm{~cm})$ polyethylene sheeting (outside diameter: $16.4 \mathrm{~m}$; volume: $126.74 \mathrm{~m}^{3}$ ). The artificial stream was also supplied with water pumped from the East branch of the Maple River $\left(20^{\circ} \mathrm{C}\right)$ that was minimally filtered using nylon knee-high stockings secured to the inflow piping using a hose clamp. Fish were visually and mechanically isolated from each other for one week prior to use in experimentation to reduce the effect of social history (Clara, Amorim, \& Almada, 2005). This containment system also ensured a homogeneous chemical and mechanical environment during the isolation phase to control for any chemical signals that may have altered behaviour. Because tilapia are known to consume algae and detritus, fish were fed commercial tilapia food pellets once daily to supplement natural food particles that entered the stream (Hickley \& Bailey, 1987; Spataru \& Zorn, 1978).

\subsection{Monitoring the health and safety of the fish}

All fish and procedures used in this experiment were approved by IACUC protocol number 1016353-1 (Bowling Green State University) and UCUA protocol number PRO00007576 (University of Michigan). To reduce the stress during transportation, fish were transferred in coolers with an aerator and water from their original housing at White Brooke Tilapia Farm. Fish that showed signs of disease, stress or injury were immediately removed from experimentation, placed in a quarantine tank with antibiotics, and closely monitored by several personnel. All healthy fish that were used in experimental trials were returned to isolation and further monitored for signs of disease, stress or injury. All fight trials were closely monitored for aggression. If fights escalated to the point of injury, the observer removed the fish from harm. At no point during these interactions were fish harmed.

\section{3 | Experimental design}

Fish were placed in priming conditions for a total of $24 \mathrm{hr}$ prior to staged, dyadic fights. Priming conditions consisted of different population compositions and ecological contexts. Using terminology consistent with Mesterton-Gibbons and Heap (2014), populations were defined as Strong-skewed or Weak-skewed. This strong and weak terminology refers to the RHP of individuals. RHP strongly correlates to the size or mass of an individual (Keeley \& Grant, 1993; Leiser, Gagliardi, \& Itzkowits, 2004). Therefore, TL 
was used as a measurement of RHP, in which large animals (4.2$5.5 \mathrm{~cm}$, range; $4.6 \pm 0.03 \mathrm{~cm}$, mean $\pm S E M$ ) were assumed to have a higher RHP than small animals $(3.2-4.1 \mathrm{~cm}$, range; $3.8 \pm 0.03 \mathrm{~cm}$, mean \pm SEM) (Barreto, Carvalho, \& Volpato, 2011). Large individuals had TL 16\%-19\% (0.67-0.88 cm, range) longer than small individuals. Strong-skewed populations included three large fish and two small fish. Conversely, weak-skewed populations had three small fish and two large fish. Ecological contexts were determined as being resource Rich or resource Poor, in which resources were shelters made of PVC pipes (outside diameter: $3.5 \mathrm{~cm}$ ) cut into 6-cm-long pieces. Resource-rich environments consisted of five shelters, and resource-poor environments consisted of a single shelter.

The experimental design consisted of two different priming conditions based on social RHP and ecological contexts: resource-Rich/ Strong-skewed (RS) populations and resource-Poor/Weak-skewed (PW) populations (Figure 1). We chose to focus on these two conditions and ignore the resource-Rich/Weak (RW) and resource-Poor/ Strong-skewed (PS) conditions because the model for these priming conditions showed inconclusive predictions for assessment (Mesterton-Gibbons \& Heap, 2014). Focusing on RS and PW populations that have clear predicted assessment strategies associated with strong and weak individuals, allowed us to increase our sample sizes and reduce the number of comparisons needed to be made across treatments.

To test the effects of differing ecological and social contexts on assessment strategy, fights were staged between dyads of fish taken from priming conditions. Fights occurred between size-matched dyads from differing priming conditions to yield three treatments: (1) $\mathrm{PW} \times \mathrm{PW},(2) \mathrm{RS} \times \mathrm{RS}$ and (3) PW $\times$ RS. Pairs of fights were always conducted with sets of animals that were size-matched within $10 \% \mathrm{TL}$ of relative size class (large: $0.0 \%-6.9 \%, 0.0-0.3 \mathrm{~cm}$, range; $0.0 \%-6.9 \%$; small: $0.0 \%-8 \%, 0.0-0.3 \mathrm{~cm}$ ) and that started in their priming conditions simultaneously. Each batch of fights, consisted of either five

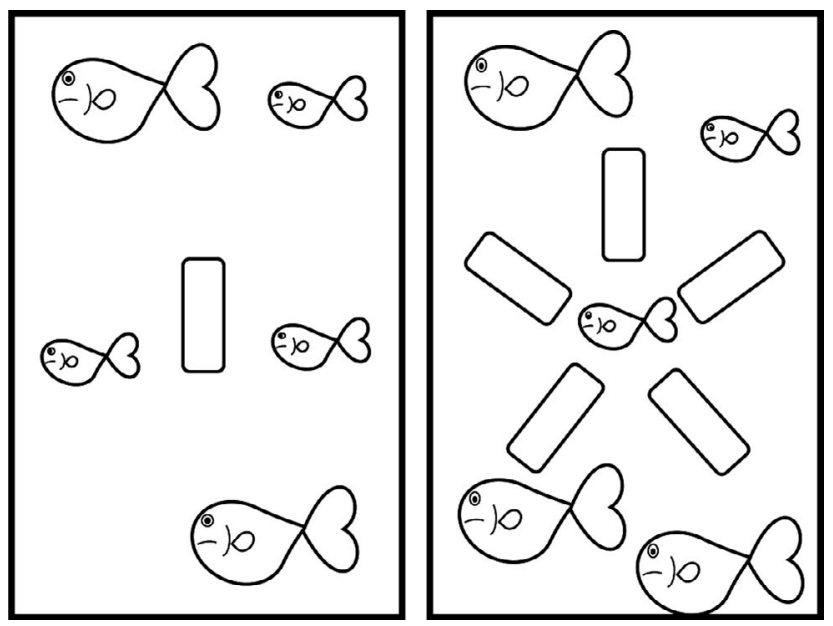

FIGURE 1 Set-up of the resource rich/strong skewed (RS) and resource poor/weak skewed (PW) priming conditions. PW (left) treatments composed of three small fish, two large fish, and one shelter, and RS (right) treatments contained two small fish, three large fish and five shelters total dyads for (PW $\times \mathrm{PW} ; \mathrm{RS} \times \mathrm{RS})$, or four total dyads from different priming conditions $(\mathrm{PW} \times \mathrm{RS}$ ). Thus, a $\mathrm{PW} \times \mathrm{PW}$ batch contained three pairs of small cichlids and two pairs of large cichlids fighting. A RS $\times$ RS batch contained three pairs of large cichlids fighting and two pairs of small cichlids fighting. Finally, a RS $\times$ PW batch only contained four fights (two paired large and two paired small) as the remaining pair was not size-matched. A total $\mathrm{N}$ of 90 fights were held, used in statistical analysis, and were distributed among the three pairings:

$\mathrm{PW} \times \mathrm{PW}: \mathrm{N}=11$ large fights, 17 small fights

RS $\times$ RS: N = 18 large fights, 12 small fights

$\mathrm{PW} \times \mathrm{RS}: \mathrm{N}=16$ large fights, 16 small fights

\subsection{Priming conditions}

The RS priming condition (three large individuals, two small individuals and five shelters) and PW priming condition (three small individuals, two large individuals and one shelter) took place in several tanks. Each tank $(51 \times 26 \times 32 \mathrm{~cm} ; \mathrm{L} \times \mathrm{W} \times \mathrm{H}$ ) contained a 2-cm deep gravel substrate, an air stone to ensure oxygenated water, and was wrapped with black canvas to reduce impacts due to extraneous visual stimuli. Plexiglas was placed on top of treatment tanks to prevent escape. Priming tanks were rinsed twice with river water before each use. Fish were fed approximately $2.5 \mathrm{hr}$ prior to transportation into these priming conditions to reduce influence of hunger-based aggression. Fish remained in the designated priming condition (RS or PW) for $24 \mathrm{hr}$ prior to fighting.

\subsection{Fight protocol}

After the priming period elapsed, fish were transferred to holding containers (dimensions: $18.1 \times 16.2 \times 7.3 \mathrm{~cm} ; \mathrm{L} \times \mathrm{W} \times \mathrm{H}$ ) before participation in fights. Each fish was then re-measured for TL and pseudorandomly paired (size matched) with a fish from the other treatment tank to produce large and small fights for every treatment. For each fight, a modified 5-gallon aquarium (fight arena) $(41 \times 21 \times 26 \mathrm{~cm}$; $\mathrm{L} \times \mathrm{W} \times \mathrm{H}$ ) was filled with $15 \mathrm{~L}$ of river water, and a camera (Sony; Model \# HDR-CX405) was placed approximately $40 \mathrm{~cm}$ from the front of the arena. The fight arena contained a black, opaque Plexiglas partition that separated the tank into two equal halves which physically, visually and chemically isolated opponents. The arena was also wrapped with black canvas to reduce the influence of extraneous visual stimuli. Each fish was placed into their respective side of the partition and allowed to acclimate for $15 \mathrm{~min}$ to reduce the stress from handling (Brian Wisenden, Ph.D., personal communication). After acclimation, the partition was removed, and the fish were allowed to interact for $10 \mathrm{~min}$. After the 10-min time period, each fish was removed from the fighting arena and placed into a community tank. For this study, each fish only fought one time. Between each trial, fight tanks and partitions were rinsed twice with river water.

\subsection{Quantification of behaviour}

Video footage was analysed by a researcher blind to treatments. All fights were evaluated based on a modified ethogram by Enquist, 
TAB LE 1 Ethogram for cichlid social behaviour; modified from Enquist et al., 1990

\begin{tabular}{|lll}
\hline Intensity & Behaviour name & $\begin{array}{c}\text { Behaviour description } \\
\text { Display at } 90 \text { degrees to opponent with all fins spread, usu- } \\
\text { ally a precursor to tail beating }\end{array}$ \\
\hline 2 & Tail beating & $\begin{array}{c}\text { One fish beats tail and pushes water with tail (typically at } \\
\text { the opponent) }\end{array}$ \\
\hline 3 & Opercular spread & $\begin{array}{c}\text { While facing rival, one fish extends operculae forward in a } \\
\text { flaring motion }\end{array}$ \\
\hline 4 & Circling & $\begin{array}{c}\text { Both opponents swim fast in a circle trying to bite each } \\
\text { other }\end{array}$ \\
\hline 5 & Mouth wrestling & $\begin{array}{c}\text { Attack; the mouth of one fish hits the other fish somewhere } \\
\text { (but not mouth-on-mouth) }\end{array}$ \\
\hline 6 & Biting & The two fish grip each other's mouths and push/pull \\
\hline 7 & Chase & One fish pursues the other for more than three body lengths \\
\hline
\end{tabular}

Leimar, Jungberg, Mallner, and Segerdahl (1990) (Table 1). Non-escalated (less intense) behaviours were defined as non-contact behaviours (i.e., tail beating, circling, displays), whereas escalated (more intense) behaviours were defined as behaviours involving physical contact (i.e., biting, mouth wresting), with the exception of a chase. If one animal performed any escalated behaviours, the dyad was defined as being in the escalated state. Each trial consisted of one fight. Within this fight, there were periods of interactions (termed bouts) and periods with no interactions. The beginning of a bout was defined as the point where one fish performed any agonistic behaviour (typically a display) within three body lengths distance from the other opponent. The end of a bout was defined when one fish retreated $\geq 3$ body lengths distance for $\geq 10 \mathrm{~s}$.

Within each fight, only the first bout was examined as dominance was established rather quickly. Fights prior to the establishment of dominance within the pair of fish have a different temporal and intensity structure than those fights that occurred after dominance has been established (Earley et al., 2006; Oliveira \& Almada, 1998). The first bout was observed for total duration, total time spent in an escalated state, and total time spent non-escalated. The winner of the bout was determined to be the animal that persisted and was dominant in stance (i.e., fins flared more outward and position in view of opponent), whereas losers were defined as the fish that retreated from the bout and were positioned in a submissive posture (i.e., fins flushed against body, as viewed from the opponent). Dominant fish were defined as the animal that consistently chased/pursued the opponent both within the bout and subsequent interactions within the 10-min sampling period. Submissive fish consistently retreated from interactions with the opponent.

\section{7 | Statistical analysis}

One of the diagnostics for identifying differences in assessment strategies is the regression between contest duration (or escalated and non-escalated durations) versus absolute winner animal body size (Arnott \& Elwood, 2009; Taylor \& Elwood, 2003). Regressions may also be utilized to determine the relationship between loser animal body size and RHP difference (Arnott \& Elwood, 2009;
Taylor \& Elwood, 2003). However, the relationship between duration of contest with either RHP difference in opponents or loser size is predicted to be identical (i.e., same slope) for both mutual and self-assessment (Arnott \& Elwood, 2009), thus these analyses do not provide any additional information that allows discernment of a specific assessment strategy. We performed an ANCOVA to assess significant differences across priming treatments for winner body size. Before any ANCOVAs were performed, all dependent variables were evaluated for outliers and collinearity through the implementation of methods described in Zuur, leno, Walker, Saveliev, \& Smith, (2009). The ANCOVA model was constructed using total duration of the fight regressed against winner total length, with priming treatment ( 3 conditions) and individual size ( 2 conditions) as categorical variables (Chambers, Freeny, \& Heiberger, 1992). A Tukey HSD comparison was implemented subsequent any significant differences that existed (Hothorn, Bretz, \& Westfall, 2008). All analyses on contest durations were conducted using R statistical software (version 3.3.0) (R Development Core Team, 2016). In addition, because assessment strategies are theoretically driven by the loser within a contest, we subdivided our PW $\times$ RS treatments based on the loser's priming treatment as well as size of the fish. This subset of data underwent another regression analysis using the winner's total body length as the independent variable and the duration of the fight as the dependent variable. This analysis had n's of 9 (PW loser, large fish), 9 (PW loser, small fish), 7 (RS loser, large fish) and 7 (RS loser, large fish).

Following the suggestion of the American Statistical Association on the use and misuse of $p$-values, we state all $p$-values as exact except for those values less that $p<.0001$ (Wasserstein \& Lazar, 2016). In addition, reporting the exact $p$-value as opposed to $p$ is greater than or less than .05 avoids the misinterpretation of a "bright line" at $p<.05$ as indicating significance (Greenland et al., 2016).

\section{3 | RESULTS}

\section{1 | Overall ANCOVA model}

There was an interaction between priming treatment, individual size and the winner total length for total fight durations $\left(F_{(2,78,0.05)}=46.179\right.$, 
$p<.0001$; Table 2). The Tukey HSD post hoc results revealed several differences between the treatments (Table 3).

\section{2 $\mathrm{PW} \times \mathrm{PW}$ treatment regressions}

The fight durations from the PW treatments exhibited strong linear regressions of contest duration and winner total length (PW-Large, $r^{2}=0.85$ and PW-Small, $r^{2}=0.78$; Figure 2; Table 4). The PW-Large regression had large positive slope (290), whereas the PW-Small had a negative slope (-351).

\section{3 $\quad$ RS $\times$ RS treatment regressions}

Similar to the PW priming treatments, the fight durations from the RS priming treatments exhibited strong and linear regressions of contest duration and winner total length (RS-Large, $r^{2}=0.86$ and PW-Small, $r^{2}=0.93$; Figure 2; Table 4). In contrast to the PW priming treatments, the slopes of the RS regressions were opposite to those found with the PW regressions regarding contestant size. The RS-Large priming treatment had a negative slope (-195), whereas the RS-Small had a positive slope (525).

\section{4 $\mathrm{PW} \times \mathrm{RS}$ treatment regressions}

In contrast to the similar treatment fights, the cross-treatment fights exhibited weak to no linear regressions (Figure 2; Table 4). The PW $x$ RS-Large duration regression had an $r^{2}$ of -0.07 and the PW $\times$ RSSmall had an $r^{2}$ of 0.03 . The subset analysis based on the loser's priming treatment exhibited no significant regressions (Figure 3). The $p$-values ranged from .14 to .7 .

\subsection{Comparison across priming treatments}

The interaction effect is evident in the Tukey HSD post hoc comparisons across treatments (Table 3 ). The PW-Large regression findings were different from the RS-Large $(p<.001)$ and PW-Small $(p<.001)$ but were not distinctive from the PW $\times$ RS-Large regressions $(p=.06)$. Similarly, the RS-Large regression findings were statistically different from the RS-Small $(p<.001)$, but not disparate from the PW $\times$ RS-Large regressions $(p=.33)$. The PW-Small

TABLE 2 Overall ANCOVA results for the total fight durations between priming treatment (PT), individual size (S), and the winner total length (WTL)

\begin{tabular}{|lll|}
\hline Model term & F & $p$-value \\
\hline Main effects & & \\
\hline Priming treatment & $F_{(2,85,0.05)}=8.7$ & $p<.001$ \\
\hline Individual size & $F_{(1,85,0.05)}=2.1$ & $p=.23$ \\
\hline Winner total length & $F_{(1,85,0.05)}=1.5$ & $p=.225$ \\
\hline Interaction term & & $p<.0001$ \\
\hline PT $\times S \times$ WTL & $F_{(2,78,0.05)}=46.179$ & \\
\hline
\end{tabular}

and the RS-Small had different regression results $(p<.001)$, and the RS-Small was statistically different from the regressions for the $\mathrm{PW} \times \mathrm{RS}$-Small regressions $(p<.001)$. Finally, the $\mathrm{PW} \times \mathrm{RS}$ Large regression finding was not different than the $\mathrm{PW} \times \mathrm{RS}$-Small regression $(p=.82)$.

\section{6 | Statistical analysis for non-escalated durations and escalated durations}

The statistical results for the ANCOVA, Tukey HSD and regression analysis for the non-escalated durations were qualitatively not different, as the total duration analysis has not been shown for brevity. Conversely, the statistical analysis for the escalated durations showed $p$-values above 0.5 for all the comparisons.

\section{4 | DISCUSSION}

When comparing our results to the framework developed by Mesterton-Gibbons and Heap (2014), we note the findings from this study yield interesting conclusions regarding assessment strategies. Cichlids of different sizes adopted different assessment strategies, even within the same priming treatment (Table 3). Large cichlids kept in a resource-rich/strong-skewed (RS) population appear to be employing a mutual assessment strategy while fighting size-matched individuals, because the duration versus winner total length regression produced a negative slope (Figure 2; Tables 3 and 4). Conversely, small cichlids primed in the same environment (RS) seem to be utilizing self-assessment, as the slope on this regression was positive (Figure 2; Tables 3 and 4). When cichlids were kept in a resource-poor/weak-skewed (PW) population, the slopes between size classes were inverse of the fish from RS settings. Large cichlids exhibited a positive slope, and small cichlids demonstrated a negative slope on the duration versus winner total length analysis (Figure 2; Tables 3 and 4). The assessment strategies in PW conditions were also opposite of those concluded from the

TAB LE 3 Statistical results for the Tukey HSD post hoc tests for planned comparisons between the regressions for different priming treatments. The word "cross" within the comparison treatment column refers to the PW versus RS fights

\begin{tabular}{lll}
\hline Treatment & Comparison Treatment & $p$-value \\
\hline PW-Large & RS-Large & $p<.001$ \\
\hline PW-Large & Cross-Large & $p=.06$ \\
\hline PW-Large & PW-Small & $p<.001$ \\
\hline RS-Large & Cross-Large & $p=.33$ \\
\hline RS-Large & RS-Small & $p<.001$ \\
\hline Cross-Large & Cross-Small & $p=.82$ \\
\hline PW-Small & RS-Small & $p<.001$ \\
\hline PW-Small & Cross-Small & $p=.66$ \\
\hline RS-Small & Cross-Small & $p<.001$ \\
\hline
\end{tabular}




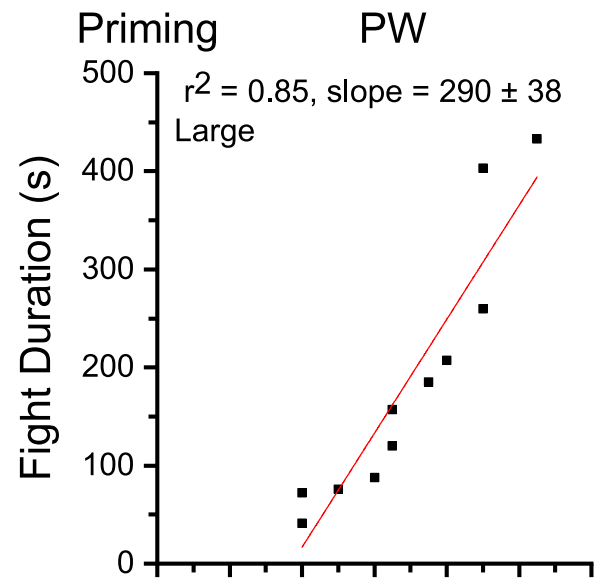

RS
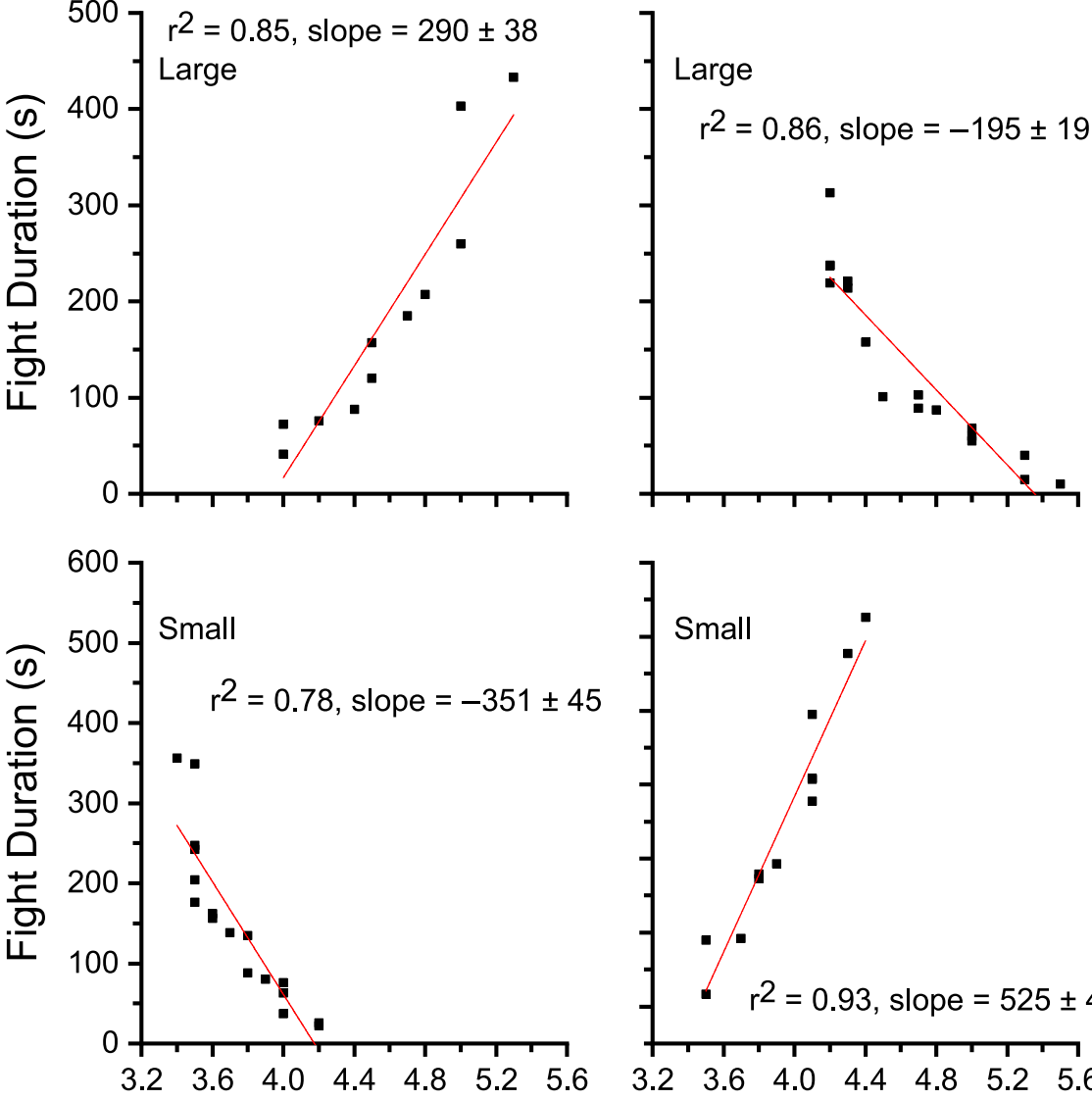

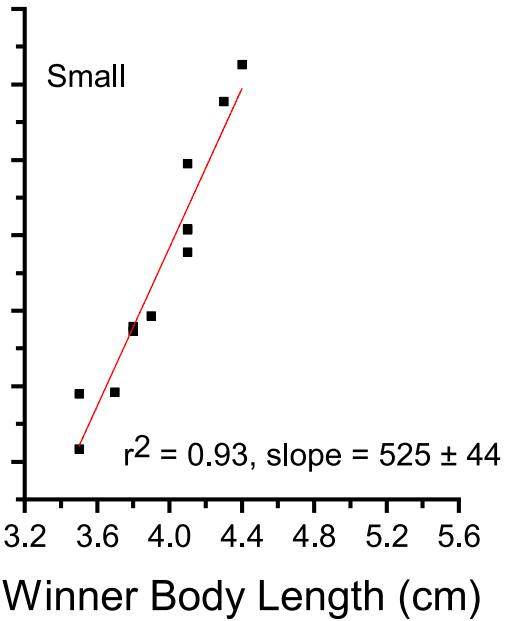

PW x RS
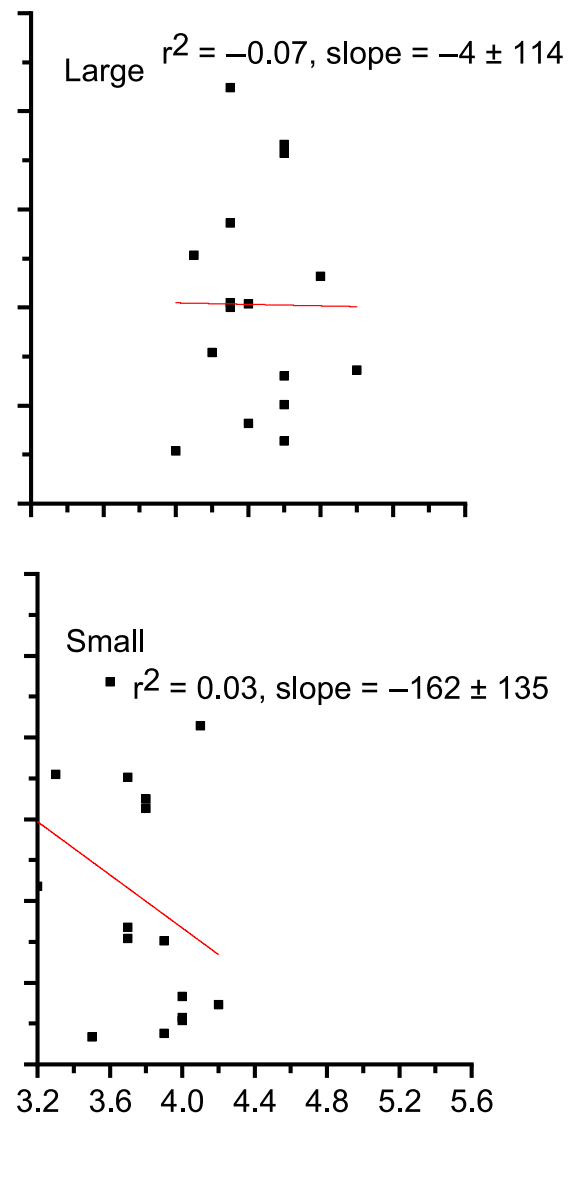

FIGURE 2 Regression results from the total duration versus winner total length for the different priming treatments and cichlid sizes. The top row displays all the regressions for the large fish within each treatment and the bottom row displays the regressions from the small fish in each treatment. The different priming treatments are contained within the different columns of graphs where the PW treatment is the left-hand column, the RS treatment is found in the middle column, and the PW $x$ RS treatment is found in the right-hand column. The $r^{2}$ and slopes for the regression fits are found within the graph, and the $p$-values for the fits are found in Table 4 [Colour figure can be viewed at wileyonlinelibrary.com]

TAB LE 4 Statistical outcomes for the regressions of total duration versus winner total length for the six priming treatments

\begin{tabular}{llcrl} 
Treatment & Individual Size & \multicolumn{1}{l}{$r^{2}$} & Slope & $p$-value \\
\hline $\mathrm{PW} \times \mathrm{PW}$ & Large & 0.85 & 290 & $p<.01$ \\
$\mathrm{PW} \times \mathrm{PW}$ & Small & 0.78 & -351 & $p<.01$ \\
\hline $\mathrm{RS} \times \mathrm{RS}$ & Large & 0.86 & -195 & $p<.01$ \\
\hline $\mathrm{RS} \times \mathrm{RS}$ & Small & 0.93 & 525 & $p<.01$ \\
\hline $\mathrm{PW} \times \mathrm{RS}$ & Large & -0.07 & -4 & $p=.97$ \\
$\mathrm{PW} \times \mathrm{RS}$ & Small & 0.03 & -162 & $p=.25$ \\
\hline
\end{tabular}

RS environment, as large cichlids in the PW treatment seem to be using self-assessment whereas small individuals appear to employ mutual assessment. Therefore, fish primed within opposite contexts are also applying converse assessment strategies. There was no regression relationship from the fights paired with individuals from RS and PW treatments (Figure 2; Tables 3 and 4), which does not lend itself to an assignment of a particular assessment strategy. Cichlids kept in different contexts did not provide a clear and discernible assessment strategy. In addition, despite the theoretical concept that assessment strategies should be driven by the loser, the analysis of the fights that occurred between fish from different priming treatments did not show any significant effect (Figure 3). Taken together, these findings indicate that the assessment strategy employed by cichlids changed as a result of either the social or ecological priming treatments alone or some interaction between the two factors. Because the ecological (resource rich or poor) and social (strong or weak) were altered together, these results cannot show whether one or both factors are driving the results.

Assessment theory has been classically inferred as a static framework, in that the assessment strategy used by an organism is set throughout its' entire social history (Arnott \& Elwood, 2009; Elwood \& Arnott, 2012; Taylor \& Elwood, 2003). Recent theoretical analysis has suggested assessment strategies occur within a multidimensional space, including temporal changes within the lifetime of an individual or even within a single fight (Fawcett \& Mowles, 2013; 

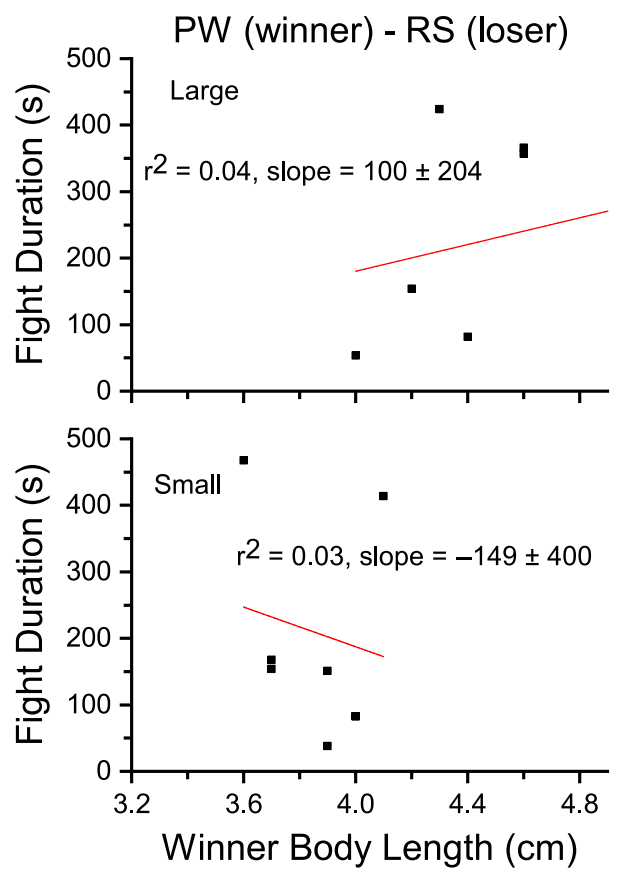
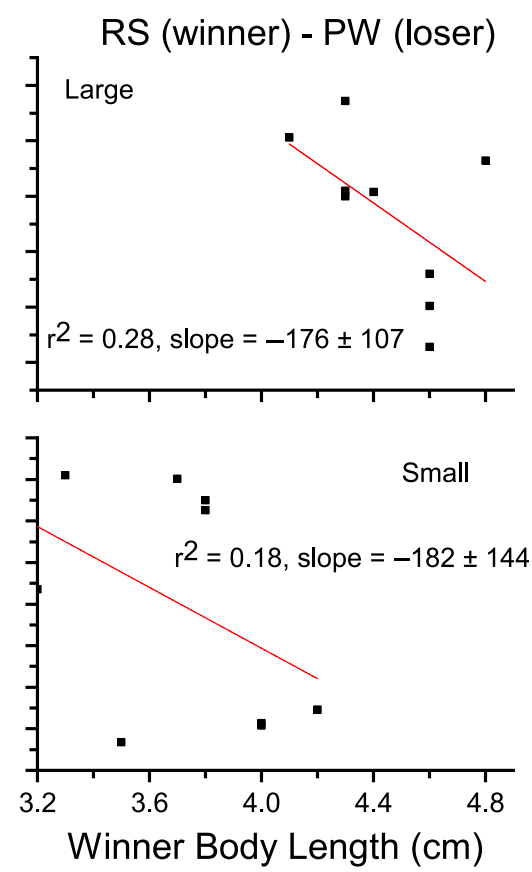

FIGURE 3 Regression results from the total duration versus winner total length for the different priming treatments and cichlid sizes. This data only include those trials that had participants from different priming treatments and are a subset of the data in Figure 3 (last column). The top row displays all the regressions for the large fish within each treatment and the bottom row displays the regressions from the small fish in each treatment. The different winners and losers are labelled above the columns. None of the regressions displayed on the graph are significant [Colour figure can be viewed at wileyonlinelibrary.com]
Mesterton-Gibbons \& Heap, 2014). Both the social and ecological environment, as well as the combination of the two elements, are dimensions within this space that influence the development of certain assessment strategies (Fawcett \& Mowles, 2013; MestertonGibbons \& Heap, 2014). Within this study, we determined that the social (RHP distribution) and ecological environments (resource density) effect the implementation of assessment across a multidimensional space and that our results are consistent with the proposed theoretical framework. Although, given the experimental design, it is not possible to determine whether the social, the ecological environment, or some interaction between these two factors are driving the change, simply put, the assessment strategy that is employed by an individual is dependent upon either one of the environments or the combination of these two environments. Assessment strategies also appear to exhibit some behavioural plasticity, as our findings suggest assessment strategies are dynamic within a species. In this case, RHP distribution and resource density modify the assessment strategy that develops from this behavioural plasticity.

Theoretical framework has also indicated that strong and weak individuals within a social group should use differing assessment strategies (Mesterton-Gibbons \& Heap, 2014). In resource-rich, strong-skewed (RS) populations, weaker individuals always withdraw (self-assessment) whereas stronger individuals only fight those they perceive as weak (mutual assessment). The prominent assessment strategy employed by populations appears to be driven by the stronger (larger) individuals in the population. Therefore, in RS populations, the effective strategy is predicted to be mutual assessment, simply because there are more strong (larger) individuals and mutual assessment is the most cost-effective strategy to utilize. The results within our study support this prediction, as large cichlids in RS $x$ RS treatments employed a mutual assessment strategy. Furthermore, the prominent assessment strategy concluded in resource-poor, weak-skewed (PW) populations is mutual assessment (Mesterton-Gibbons \& Heap, 2014). In PW populations, strong individuals fight unconditionally (self-assessment) while weak individuals only fight those they perceive as weak (mutual assessment). Our findings are in line with the predictions from these models, as the larger cichlids in the PW $x$ PW treatment (of which there were fewer total number in a treatment) are employing a self-assessment strategy, while the more numerous and smaller individuals are using mutual assessment.

Our findings deviated from the model predications when the analysis of the fish from different priming treatments was considered (Figures 2 and 3). Within these conditions, the assessment strategy displayed should be governed by the loser. The results from these fights should display a size versus duration relationship found by the losing fish primed under the same environmental conditions. This was not the case. In all instances (Figure 3), the assessment strategies being displayed by the regressions do not follow any of the predictions for either mutual or self-assessment. One possible explanation for these contradictory results is that animals from different priming treatments could be using the same assessment strategy based on different sources of information. For example, both fish could be using a form of mutual assessment. Yet, the fish from the RS treatment may be comparing energy reserves for their assessment, while the fish from the PW may be comparing fight history or experience. Thus, if the source information being used for assessment varies between animals in different treatments, the regression analysis might display a mixed assessment outcome. This would be especially true if the fish from different priming treatments have differing expectations on the meaning or sequence of displays during fights. Thus, the expectation of signals or information that are either missing or out of sequence could alter the employment of an animal's assessment strategy. 
Two schools of thought tend to dominate the discussion regarding the fundamental reasons for the development of assessment strategies. One is that costs of losing fights and benefits of winning fights are the driving force behind assessment strategy (Maynard Smith \& Price, 1973). More specifically, contestants will consider the resource value when engaging in an agonistic interaction and differentially allocate energy to a fight depending on the changeable value of a resource to the contestant (Arnott \& Elwood, 2008). The value of the resource could be determined by satiation state (i.e., if the resource is food), mating history or predatory abundance (i.e., for shelters) (Arnott \& Elwood, 2008; Enquist \& Leimar, 1987; Maynard Smith, 1982; Maynard Smith $\&$ Parker, 1976). The perceived value of a resource can interact with intrinsic fighting ability to drive contest dynamics (Lane \& Briffa, 2018). In addition, early environmental influences as well as experience in social situations also play a role in fight dynamics. Enriched environments interacted with previous experience to determine fight dynamics (Arnold \& Taborsky, 2010). The second topic is that the information available to the animal from fighting is the driving force behind assessment strategy (Elwood \& Arnott, 2012; Mesterton-Gibbons \& Heap, 2014). Animals utilize either solely private information about fighting ability (pure self-assessment) or consider both private and public information about fighting ability of oneself versus the fighting ability of an opponent. Yet, this dichotomy (private vs. public) lies along a spectrum (Prenter et al., 2006). Our results show that the social and/or ecological environment influences where contests fall along that spectrum. Therefore, recognizing that either costs and benefits (ecological factors) or information availability (social factors) as the main driving force, fails to fully capture the complexity of the interaction between these two priming components. As demonstrated in this study, the development and use of an assessment strategy is dependent on the individual's social history, ecological environment or an interaction of both conditions.

A possible mechanistic explanation for our findings might be found within the concept of information use. If fish from different priming treatments are using different combinations or sources of information (public and private), then facing an opponent from a different priming treatment could mean a confusing source of public information. Fish raised within a resource-rich environment with large individuals may adopt a set of social signals and/or displays that are different than fish raised in other environments. The expectation of fish for a certain type or sequence of signals may be set by the environment in which the animal was primed. Thus, public information and its use could be involved by the priming environments. If so, it would be expected that fish from differing priming environments may have different sets of public displays on which mutual assessment is based (van Bergen, Coolen, \& Laland, 2004; Webster \& Laland, 2008). If this mechanism is in operation, then it is possible to predict that the social environment may be the more important factor in determining assessment strategies.

Natural selection favours and influences fighting ability, but also acts on the capacity to acquire and utilize information (i.e., assessment). The interaction between the importance of winning the fight in order to obtain resources and probability of winning a fight changes as a function of ecological and social context. Environments are constantly fluctuating, in both resource abundance and the social construct of populations. Natural selection should favour individuals that can detect subtle differences in these two factors and alter assessment strategies in accordance to environmental changes. Therefore, as the environment alters (both socially and ecologically), assessment strategies should also change. For example, weaker individuals in a population where the RHP distribution is strong-skewed may benefit more from utilizing a self-assessment strategy because acquiring information about opponents comes at the cost of giving up information about how weak that individual is (MestertonGibbons \& Heap, 2014). However, in a weak-skewed population, weaker individuals may benefit more from using a mutual assessment strategy, considering these animals may save energy and only engage in contests with a high probability of winning.

Aside from resource availability and social construct of populations, other environmental factors have the potential to change the selective landscape under which assessment strategies develop. The presence of other competitors and predators can change what assessment strategy is employed by individuals. When private information is recent and reliable, sticklebacks will utilize private information over public information to base their foraging decisions in patches (van Bergen et al., 2004). However, private information on patch quality is much more costly to obtain when under heavy predation pressure (Webster \& Laland, 2008), thus sticklebacks may rely heavily on public information to avoid consumption by predators and forage effectively (Coolen, Bergen, Day, \& Laland, 2003). Public information may also be more valuable when individuals are selecting habitats for reproduction, as public information is highly predictive on the reproductive success of the conspecifics in the patch (Doligez, Cadet, Danchin, \& Boulinier, 2003). The probability that public information concludes reproductive success is lower than expected, possibly due to the potential of aggregation or patch quality for foraging success (Doligez et al., 2003). Therefore, the use of public and private information by an individual is a spectrum, and the position some individual holds is dependent on resource value and predation risk. Indeed, recent work concluded that there is an increasing need to combine intrinsic (e.g., RHP or size) and extrinsic conditions (e.g., resource abundance) to create a more complete view of fighting behaviours (Lane \& Briffa, 2018).

Overall, the results of this study suggest that a new theoretical framework should be accepted for assessment strategies. The consideration of assessment strategies as a fixed, static concept is no longer appropriate and fails to fully represent natural systems. As the ecological and social landscape changes for an individual, the appropriate assessment strategy likewise alters. Research on assessment strategies and animal behaviour predictive models should include these environmental contexts because, as demonstrated, assessment strategy use switches based on either the social history, ecological condition, or interaction between those two factors. Moreover, altering various environmental factors and observing the 
change in assessment strategy prevalence may provide a clearer picture of the factors that are most influential on the fluctuation of assessment strategies.

\section{ACKNOWLEDGEMENTS}

The University of Michigan Biological Station provided use of facilities and funded this project through the Marian P. and David M. Gates Graduate Student Endowment Fund to S.L.S. The Bowling Green State University Faculty Research Committee for a Building Strength Award and a Fulbright Fellowship to P.A.M. also helped fund this work. The authors would like to acknowledge and thank the Laboratory for Sensory Ecology for the support, edits and assistance provided throughout the entirety of this project. We would also like to thank Molly $\mathrm{C}$. Beattie for her assistance in care of the fish. Finally, this paper has been improved substantially by the review comments of Bob Elwood, Jutta Schneider and an anonymous review. We would like to thank their effort and thoughts.

\section{CONFLICT OF INTEREST}

The authors state no conflict of interest involved with this manuscript.

\section{ORCID}

Sara L. Stienecker (iD) https://orcid.org/0000-0002-7361-587X

Paul A. Moore (iD https://orcid.org/0000-0002-4555-1178

\section{REFERENCES}

Arnold, C., \& Taborsky, B. (2010). Social experience in early ontogeny has lasting effects on social skills in cooperatively breeding cichlids. Animal Behaviour, 79(3), 621-630. https://doi.org/10.1016/j.anbeh av.2009.12.008

Arnott, G., \& Elwood, R. W. (2007). Fighting for shells: How private information about resource value changes hermit crab pre-fight displays and escalated fight behavior. Proceedings of the Royal Society B, 274, 3011-3017.

Arnott, G., \& Elwood, R. W. (2008). Information gathering and decision making about resource value in animal contests. Animal Behaviour, 76, 529-542. https://doi.org/10.1016/j.anbehav.2008.04.019

Arnott, G., \& Elwood, R. W. (2009). Assessment of fighting ability in animal contests. Animal Behaviour, 77, 991-1004. https://doi. org/10.1016/j.anbehav.2009.02.010

Barreto, R. E., Carvalho, G. G. A., \& Volpato, G. L. (2011). The aggressive behavior of Nile tilapia introduced into novel environments with variation in enrichment. Zoology, 114(1), 53-57. https://doi. org/10.1016/j.zool.2010.09.001

Bertram, S. M., Rook, V. L., Fitzsimmons, J. M., \& Fitzsimons, L. P. (2011). Fine- and broad-scale approaches to understanding the evolution of aggression in crickets. Ethology, 117, 1067-1080. https://doi. org/10.1111/j.1439-0310.2011.01970.x

Camerlink, I., Turner, S. P., Farish, M., \& Arnott, G. (2017). The influence of experience on contest assessment strategies. Scientific Reports, 7(1), 14492. https://doi.org/10.1038/s41598-017-15144-8
Chambers, J. M., Freeny, A., \& Heiberger, R. M. (1992). Analysis of variance; designed experiments. In J. M. Chambers \& T. J. Hastie (Eds.), Statistical models in S. Pacific Grove, CA: Wadsworth \& Brooks/Cole.

Chase, I. D., Tovey, C., Spangler-Martin, D., \& Manfredonia, M. (2002). Individual differences versus social dynamics in the formation of animal dominance hierarchies. Proceedings of the National Academy of Sciences, 99(8), 5744-5749. https://doi.org/10.1073/pnas.08210 4199

Clara, M., Amorim, P., \& Almada, V. C. (2005). The outcome of male-male encounters affects subsequent sound production during courtship in the cichlid fish Oreochromis mossambicus. Animal Behaviour, 69, 595-601. https://doi.org/10.1016/j.anbehav.2004.06.016

Clutton-Brock, T. H., \& Albon, S. D. (1979). The roaring of red deer and the evolution of honest advertisement. Behaviour, 69(3), 145-170. https://doi.org/10.1163/156853979X00449

Coolen, I., van Bergen, Y., Day, R. L., \& Laland, K. N. (2003). Species difference in adaptive use of public information by sticklebacks. Proceedings of the Royal Society B: Biological Sciences, 270, 2413-2419.

Dabelsteen, T. (2005). Public, private or anonymous? Facilitating and countering eavesdropping. In P. K. McGregor (Ed.), Animal communication networks (pp. 38-62). New York, NY: Cambridge University Press.

Doligez, B., Cadet, C., Danchin, E., \& Boulinier, T. (2003). When to use public information for breeding habitat selection? The role of environmental predictability and density dependence. Animal Behaviour, 66, 973-988. https://doi.org/10.1006/anbe.2002.2270

Doutrelant, C., \& McGregor, P. K. (2000). Eavesdropping and mate choice in female fighting fish. Behaviour, 137, 1655-1669. https://doi. org/10.1163/156853900502763

Doutrelant, C., McGregor, P. K., \& Oliveira, R. F. (2001). The effect of an audience on intrasexual communication in male Siamese fighting fish, Betta Splendens. Behavioral Ecology, 12(3), 238-286. https://doi. org/10.1093/beheco/12.3.283

Earley, R. L., Edwards, J. T., Aseem, O., Felton, K., Blumer, L. S., Karom, M., \& Grober, M. S. (2006). Social interactions tune aggression and stress responsiveness in a territorial cichlid fish (Archocentrus nigrofasciatus). Physiology \& Behavior, 88(4-5), 353-363. https://doi. org/10.1016/j.physbeh.2006.04.002

Elias, D. O., Kasumovic, M. M., Punzalan, D., Andrade, M. C. B., \& Mason, A. C. (2008). Assessment during aggressive contests between male jumping spiders. Animal Behaviour, 76, 901-910. https://doi. org/10.1016/j.anbehav.2008.01.032

Elwood, R. W., \& Arnott, G. (2012). Understanding how animals fight with Lloyd Morgan's canon. Animal Behaviour, 84, 1095-1102. https ://doi.org/10.1016/j.anbehav.2012.08.035

Enquist, M., \& Leimar, O. (1983). Evolution of fighting behavior: Decision rules and assessment of relative strength. Journal of Theoretical Biology, 102, 387-410.

Enquist, M., \& Leimar, O. (1987). Evolution of fighting behavior: The effect of variation in resource value. Journal of Theoretical Biology, 127, 187-205.

Enquist, M., Leimar, O., Jungberg, T. L., Mallner, Y., \& Segerdahl, N. (1990). A test of the sequential assessment game: Fighting in the cichlid fish Nannacara anomala. Animal Behaviour, 40, 1-14. https:// doi.org/10.1016/S0003-3472(05)80660-8

Fawcett, T. W., \& Mowles, S. L. (2013). Assessments of fighting ability need not be cognitively complex. Animal Behaviour, 86, e1-e7. https ://doi.org/10.1016/j.anbehav.2013.05.033

Fitzsimmons, L. P., \& Bertram, S. M. (2013). Playing to an audience: The social environment influences aggression and victory displays. Biology Letters, 9, 20130449. https://doi.org/10.1098/rsbl.2013.0449

Greenland, S., Senn, S. J., Rothman, K. J., Carlin, J. B., Poole, C., Goodman, S. N., \& Altman, D. G. (2016). Statistical tests, P values, confidence intervals, and power: $\mathrm{A}$ guide to misinterpretations. European 
Journal of Epidemiology, 31(4), 337-350. https://doi.org/10.1007/ s10654-016-0149-3

Hack, M. A. (1997a). The energetic costs of fighting in the house cricket, Acheta domesticus L. Behavioural Ecology, 8, 28-36.

Hack, M. A. (1997b). Assessment strategies in the contests of male crickets, Acheta domesticus (L.). Animal Behaviour, 53(4), 733-747. https:// doi.org/10.1006/anbe.1996.0310

Hickley, P., \& Bailey, R. G. (1987). Food and feeding relationships of fish in the Sudd swamps (River Nile, southern Sudan). Journal of Fish Biology, 30(2), 147-159. https://doi.org/10.1111/j.1095-8649.1987.tb057 41. $x$

Hothorn, T., Bretz, F., \& Westfall, P. (2008). Simultaneous inference in general parametric models. Biometrical Journal, 50(3), 346-363. https://doi.org/10.1002/bimj.200810425

Hsu, Y., Earley, R. L., \& Wolf, L. L. (2006). Modulation of aggressive behavior by fighting experience: Mechanisms and contest outcomes. Biology Reviews, 81, 33-74.

Hsu, Y., Lee, S.-P., Chen, M.-H., Yang, S.-Y., \& Cheng, K.-C. (2008). Switching assessment strategy during a contest: Fighting in killifish Kryptolebias marmoratus. Animal Behaviour, 75, 1641-1649. https:// doi.org/10.1016/j.anbehav.2007.10.017

Jennings, D. J., \& Gammel, M. P. (2013). Contest behavior in ungulates. In I. C. W. Hardy \& M. Briffa (Eds.), Animal contests (pp. 304-320). New York, NY: Cambridge University Press.

Johnsson, J. I., \& Åkerman, A. (1998). Watch and learn: Preview of the fighting ability of opponents alters contest behavior in rainbow trout. Animal Behaviour, 56, 771-776.

Keeley, E. R., \& Grant, J. W. A. (1993). Visual information, resource value, and sequential assessment in convict cichlid (Cichlasoma nigrofasciatum) contests. Behavioral Ecology, 4(4), 345-349.

Kokko, H. (2013). Dyadic contests: Modelling fights between two individuals. In I. C. W. Hardy \& M. Briffa (Eds.), Animal contests (pp. 5-32). New York, NY: Cambridge University Press.

Lane, S. M., \& Briffa, M. (2018). How does the environment affect fighting? The interaction between extrinsic fighting ability and resource value during contests. Journal of Experimental Biology, 221(19), jeb187740. https://doi.org/10.1242/jeb.187740

Leiser, J. K., Gagliardi, J. L., \& Itzkowits, M. (2004). Does size matter? Assessment and fighting in small and large size-matched pairs of adult male convict cichlids. Journal of Fish Biology, 64, 1339-1350. https://doi.org/10.1111/j.0022-1112.2004.00399.x

Lougue, D. M., Abiola, I. O., Rains, D., Bailey, N. W., Zuk, M., \& Cade, W. H. (2010). Does signaling mitigate the cost of agonistic interactions? A test in a cricket that has lost its song. Proceedings of the Royal Society of London B, 277(1693), 2571-2575.

Matos, R. J., \& Schlupp, I. (2005). Performing in front of an audience: Signalers and the social environment. In McGregor (Ed.), Animal communication networks (pp. 63-83). New York, NY: Cambridge University Press.

Maynard Smith, J. (1974). The theory of games and the evolution of animal conflicts. Journal of Theoretical Biology, 47, 209-221. https://doi. org/10.1016/0022-5193(74)90110-6

Maynard Smith, J. (1982). The theory of games. Cambridge, UK: Cambridge University.

Maynard Smith, J., \& Parker, G. A. (1976). The logic of asymmetric contests. Animal Behaviour, 24, 159-175. https://doi.org/10.1016/ S0003-3472(76)80110-8

Maynard Smith, J., \& Price, G. R. (1973). The logic of animal conflict. Nature, 246, 15-18. https://doi.org/10.1038/246015a0
Mesterton-Gibbons, M., \& Heap, S. M. (2014). Variation between selfand mutual assessment in animal contests. The American Naturalist, 183(2), 199-213. https://doi.org/10.1086/674443

Mesterton-Gibbons, M., \& Sherratt, T. N. (2006). Coalition formation: A game-theoretic analysis. Behavioral Ecology, 18(2), 277-286. https:// doi.org/10.1093/beheco/arl084

Montroy, K., Loranger, M. J., \& Bertram, S. M. (2016). Male crickets adjust their aggressive behavior when a female is present. Behavioural Processes, 124, 108-114. https://doi.org/10.1016/j. beproc.2015.11.003

Oliveira, R. F., \& Almada, V. C. (1998). Dynamics of social interactions during group formation in male of the cichlid fish Oreochromis mossambicus. Acta Ethologica, 1(1-2), 57-70.

Otter, K. A., \& Ratcliffe, L. (2005). Enlightened decisions: Female assessment and communication networks. In P. K. McGregor (Ed.), Animal communication networks (pp. 133-151). New York, NY: Cambridge University Press.

Parker, G. A. (1974). Assessment strategy and the evolution of fighting behaviour. Journal of Theoretical Biology, 47, 223-243. https://doi. org/10.1016/0022-5193(74)90111-8

Prenter, J., Elwood, R. W., \& Taylor, P. W. (2006). Self-assessment by males during energetically costly contests over precopula females in amphipods. Animal Behaviour, 72, 861-868. https://doi.org/10.1016/j. anbehav.2006.01.023

Pulliam, H. R. (1998). Sources, sinks, and population regulation. The American Naturalist, 132(50), 652-661.

R Development Core Team (2016). R: A language and environment for statistical computing. Vienna, Austria: R Foundation for Statistical Computing. http://www.R-project.org/.

Sherratt, T. N., \& Mesterton-Gibbons, M. (2013). Models of group or multi-party contests. In I. C. W. Hardy \& M. Briffa (Eds.), Animal contests (pp. 33-46). New York, NY: Cambridge University Press.

Spataru, P., \& Zorn, M. (1978). Food and feeding habits of Tilapia aurea (Steindachner) (Cichlidae) in Lake Kinneret (Israel). Aquaculture, 13, 67-79. https://doi.org/10.1016/0044-8486(78)90129-1

Taylor, P. W., \& Elwood, R. W. (2003). The mismeasure of animal contests. Animal Behaviour, 65, 1195-1202. https://doi.org/10.1006/ anbe.2003.2169

van Bergen, Y., Coolen, I., \& Laland, K. N. (2004). Nine-spined sticklebacks exploit the most reliable source when public and private information conflict. Proceedings of the Royal Society of London B, 271, 957-962.

Wasserstein, R. L., \& Lazar, N. A. (2016). The ASA's statement on pValues: Context, process, and purpose. The American Statistician, 70(2), 129-133.

Webster, M. M., \& Laland, K. N. (2008). Social learning strategies and predation risk: Minnows copy only when using private information would be costly. Proceedings of the Royal Society B, 275, 2869-2876.

Zuur, A., leno, E. N., Walker, N., Saveliev, A. A., \& Smith, G. M. (2009). Mixed effects models and extensions in ecology with R. New York, NY: Springer Science \& Business Media.

How to cite this article: Stienecker SL, Jackson KM, Moore PA. The role of social and/or ecological contexts influences assessment strategy use in Tilapia. Ethology. 2019;125:821831. https://doi.org/10.1111/eth.12936 